\title{
Numerical Assessment of a One-Mass Spring-Based Electromagnetic Energy Harvester on a Vibrating Object
}

\author{
Min-Chie CHIU ${ }^{(1)}$, Ying-Chun CHANG ${ }^{(2)}$, Long-Jyi YEH $^{(2)}$, Chiu-Hung CHUNG ${ }^{(2)}$ \\ (1) Department of Mechanical and Automation Engineering, Chung Chou University of Science and Technology
} No. 6, Lane 2, Sec. 3, Shanchiao Rd., Yuanlin, Changhua 51003, Taiwan, ROC; e-mail: minchie.chiu@msa.hinet.net

(2) Department of Mechanical Engineering, Tatung University

No. 40, Sec. 3, Zhongshan N.Rd., Taipei 104, Taiwan, ROC

(received March 5, 2014; accepted November 10, 2015)

\begin{abstract}
The paper is an exploration of the optimal design parameters of a space-constrained electromagnetic vibration-based generator. An electromagnetic energy harvester is composed of a coiled polyoxymethylen circular shell, a cylindrical NdFeB magnet, and a pair of helical springs. The magnet is vertically confined between the helical springs that serve as a vibrator. The electrical power connected to the coil is actuated when the energy harvester is vibrated by an external force causing the vibrator to periodically move through the coil. The primary factors of the electrical power generated from the energy harvester include a magnet, a spring, a coil, an excited frequency, an excited amplitude, and a design space. In order to obtain maximal electrical power during the excitation period, it is necessary to set the system's natural frequency equal to the external forcing frequency. There are ten design factors of the energy harvester including the magnet diameter $\left(D_{m}\right)$, the magnet height $\left(H_{m}\right)$, the system damping ratio $\left(\zeta_{\text {sys }}\right)$, the spring diameter $\left(D_{s}\right)$, the diameter of the spring wire $\left(d_{s}\right)$, the spring length $\left(\ell_{s}\right)$, the pitch of the spring $\left(p_{s}\right)$, the spring's number of revolutions $\left(N_{s}\right)$, the coil diameter $\left(D_{c}\right)$, the diameter of the coil wire $\left(d_{c}\right)$, and the coil's number of revolutions $\left(N_{c}\right)$. Because of the mutual effects of the above factors, searching for the appropriate design parameters within a constrained space is complicated. Concerning their geometric allocation, the above ten design parameters are reduced to four $\left(D_{m}, H_{m}, \zeta_{\text {sys }}\right.$, and $\left.N_{c}\right)$. In order to search for optimal electrical power, the objective function of the electrical power is maximized by adjusting the four design parameters $\left(D_{m}, H_{m}, \zeta_{\mathrm{sys}}\right.$, and $\left.N_{c}\right)$ via the simulated annealing method.

Consequently, the optimal design parameters of $D_{m}, H_{m}, \zeta_{\mathrm{sys}}$, and $N_{c}$ that produce maximum electrical power for an electromagnetic energy harvester are found.
\end{abstract}

Keywords: spring; harvester; generator; permanent magnet; simulated annealing; optimization; buckling; fatigue.

\section{Notations}

This paper is constructed on the basis of the following notations:

\footnotetext{
$A_{c}-$ cross-section area of coil $\left[\mathrm{m}^{2}\right]$,

$A_{m}-$ cross-section area of magnet $\left[\mathrm{m}^{2}\right]$,

$B$ - flux density [T/tesla],

$B_{Z}-$ flux density at $z$-axis $[\mathrm{T}]$,

$B_{r}-$ residual flux density at z-axis $[\mathrm{T}]$,

$C_{1}, C_{2}$ - elastic constant,

$c_{e}-$ electromagnetic damping coefficient of the coil $\left[\mathrm{N}-\mathrm{m} \mathrm{s}^{-1}\right]$,

$c_{m}-$ mechanical damping coefficient $\left[\mathrm{N}-\mathrm{m} \mathrm{s}^{-1}\right]$,

$c_{\mathrm{sys}}-$ damping coefficient of vibration system $\left[\mathrm{N}-\mathrm{m} \mathrm{s}^{-1}\right]$,

$D_{c}-$ coil diameter $[\mathrm{m}]$,

$d_{c}-$ coil's wire diameter $[\mathrm{m}]$,
}

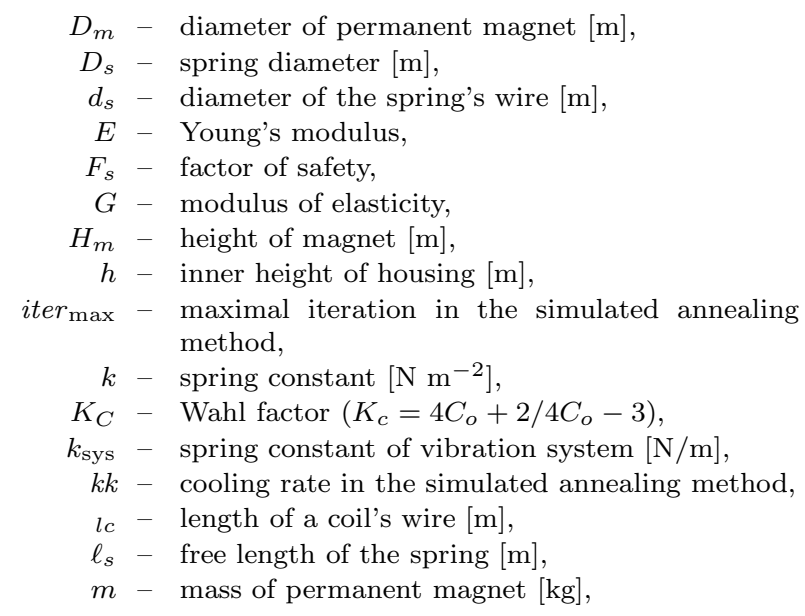




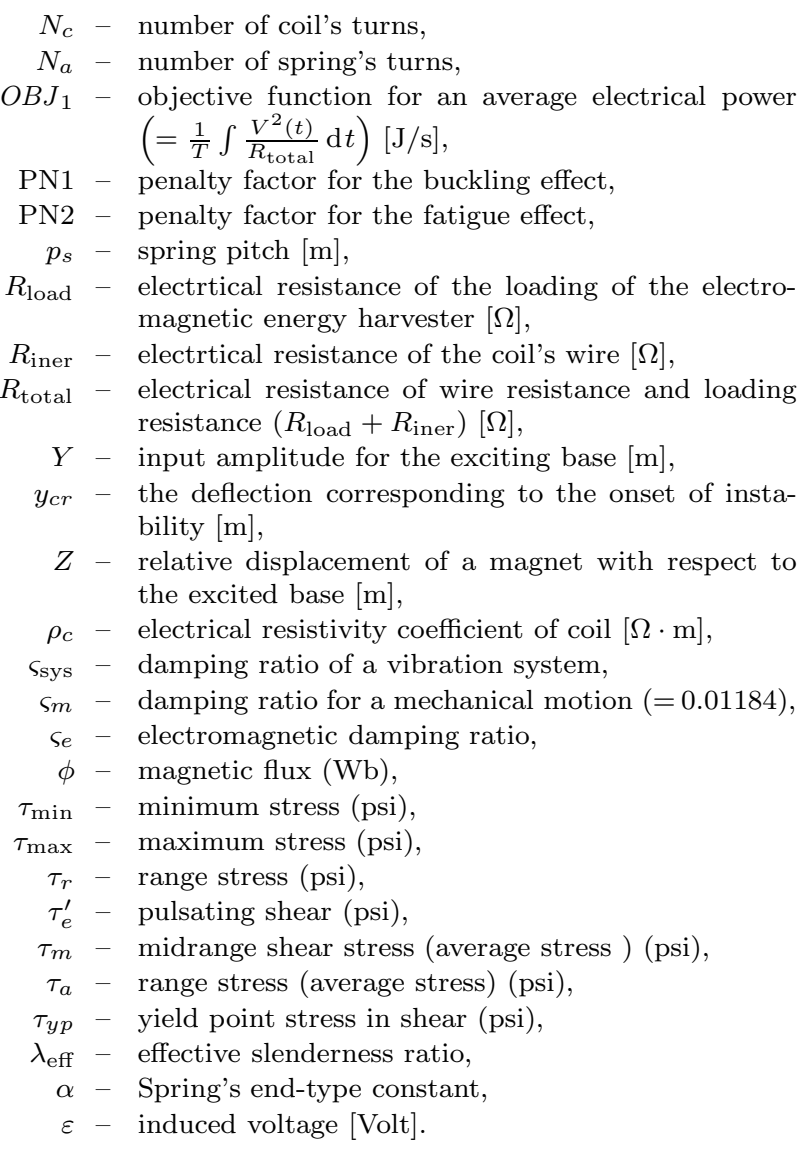

\section{Introduction}

Because electrical power for the Integrated Circuit (IC) is low, more functions for mobile devices have been developed. This, of course, results in an increase in electrical power. To extend the life of the battery, a portable charger used to supplement the battery's power is proposed. Nevertheless, the electrical power of the portable charger is also limited. So, in order to overcome the above drawbacks, a portable generator used to produce and backup the electrical power is necessary. Therefore, research in establishing small electrical generators has been initiated. Energy resources include mechanical energy, thermal energy, and potential energy. Along with this, many energy extraction methods such as the piezoelectric, electromagnetic, magnetostrictive, and electrostatic transducers have been developed (MitCHESON et al., 2004; 2008).

Williams et al. (1997) invented a wireless sensing device that was triggered by vibrational energy. This resulted in a sensor that was fixed onto a bridge to detect structural status. Later, because of progress in the semiconductor field, MEMS (PARK et al., 2010) were widely developed. Various Integrated Circuit (IC) devices with low electrical power were also created. However, the piezoelectric energy harvester has a drawback. It is fragile and therefore risky to use it at lower frequencies to extract energy of a higher vibrational amplitude. In order to extract the energy from a lower frequency vibrational source, an electromagnetic energy harvester is presented.

In previous studies (CHIU et al., 2012), exploration of a one mass electromagnetic generator has been assessed. However, a discussion of an optimal designed generator mechanism within a space-constrained situation was not addressed. Therefore, a one-mass spaceconstrained electromagnetic vibration-based generator is proposed.

In order to find an optimal mechanism for the energy harvester that produces maximal electrical power, the electrical power is set as an objective function. Here, ten design factors of the harvester including the magnet diameter $\left(D_{m}\right)$, the magnet height $\left(H_{m}\right)$, the system damping ratio $\left(\zeta_{\text {sys }}\right)$, the spring diameter $\left(D_{s}\right)$, the diameter of the spring wire $\left(d_{s}\right)$, the spring length $\left(l_{s}\right)$, the pitch of the spring $\left(p_{s}\right)$, the spring's number of revolutions $\left(N_{s}\right)$, the coil diameter $\left(D_{c}\right)$, the diameter of the coil wire $\left(d_{c}\right)$, and the coil's number of revolutions $\left(N_{c}\right)$ are established. Concerning geometric allocation, the above ten design parameters are reduced to four $\left(D_{m}\right.$ - the magnet diameter; $H_{m}-$ the magnet height; $\zeta_{\text {sys }}$ - the system damping ratio; and $N_{c}$ - the coil's number of revolutions). The optimization process is performed by adjusting the four design parameters via the simulated annealing method (Metropolis et al., 1953; KirKPATRICK et al., 1983).

\section{Mathematical models}

As indicated in Fig. 1, a vibration-based electromagnetic energy harvester will transform the mechanical energy into electrical power by using a resonant vibrating system. The electromechanical system is coupled with a one-mass mechanical vibrating motion and an electrical power equation. Based on Faraday's law of electromagnetic induction and the Lenz's law, the outputted electrical power of the coil will be proportional to the magnetic flux variance. According to the kinetic

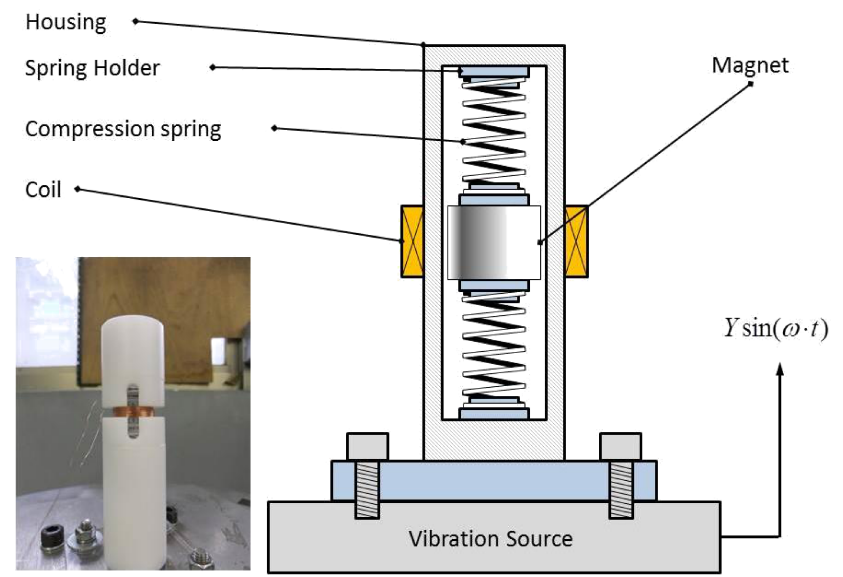

Fig. 1. A prototype of a vibration-based electromagnetic energy harvester. 
motion and the density distribution of the static magnetic field, magnetic intensity at different locations can be predicted. Also, the electrical voltage will be generated at a specified coil and a magnet position. The mathematical model for a one-mass mechanical vibration system as well as electrical power generated by the magnetic flux variance is shown below.

\subsection{Motion of the one-mass vibrational system}

A single degree of the free mechanical vibrational system is depicted in Fig. 2. The free-body diagram for a one-mass vibrational system is also shown in Fig. 2. Based on Newton's second law, the equation of motion is

$$
m \ddot{z}_{1}+c_{\mathrm{sys}}\left(\dot{z}_{1}-\dot{z}_{0}\right)+k_{\mathrm{sys}}\left(z_{1}-z_{0}\right)=0,
$$

where

$$
c_{\mathrm{sys}}=c_{m}+c_{e} \text {. }
$$

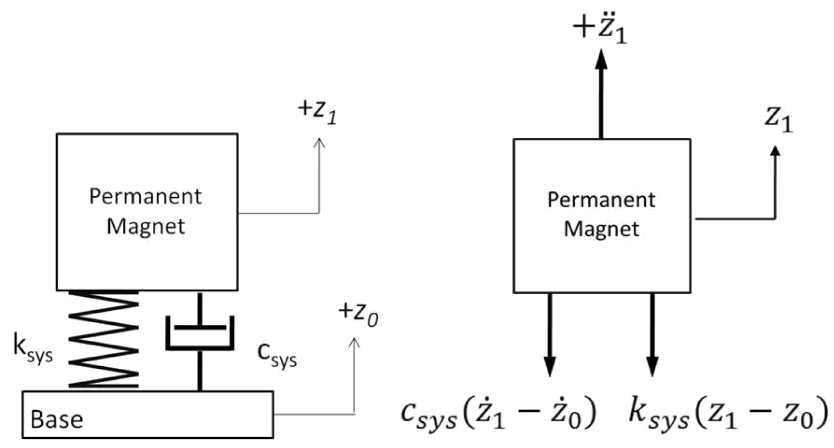

Fig. 2. A base-excitation model.

According to STEPHEN (2006), the damping coefficient $\left(c_{e}\right)$ due to the coil effect is

$$
c_{e}=\frac{(N B L)^{2}}{R_{\mathrm{load}}+\rho_{c} \frac{4 l_{c}}{\pi d_{c}^{2}}} .
$$

Assuming that the base is harmonically excited yields

$$
z_{0}=Y \sin (\omega \cdot t)
$$

The relative displacement $z$ is set at

$$
z=z_{1}-z_{0}
$$

Plugging Eqs. (3) and (4) into Eq. (1) yields

$$
m \ddot{z}+c_{\mathrm{sys}} \dot{z}+k_{\mathrm{sys}} z=m \omega^{2} Y \sin (\omega \cdot t) .
$$

The solution to Eq. (5) is

$$
z(t)=Z \sin (\omega t-\phi),
$$

where

$$
\begin{aligned}
Z & =\frac{m Y \omega^{2}}{\sqrt{\left(k-m \omega^{2}\right)^{2}+c_{\mathrm{sys}}^{2} \omega^{2}}} \\
& =Y \frac{r^{2}}{\sqrt{\left(1-r^{2}\right)^{2}+(2 r \zeta)^{2}}} \\
r & =\frac{\omega}{\omega_{n}}, \\
\phi & =\tan ^{-1}\left(\frac{c_{\mathrm{sys}} \omega}{k-m \omega^{2}}\right) .
\end{aligned}
$$

\subsection{The magnetic flux for a permanent magnet}

For a cylindrical permanent magnet, it is assumed that the inner magnetization is uniform. The coupled current method is then applied for calculating the magnetic field of the permanent magnet (MIKOLANDA, 2009) The effective current distribution is the same as an ideal solenoid. Understanding that the magnetic field is along the $\mathrm{z}$-axis only, integrating the magnetic field along the z-axis is obtained and shown in Eq. (7) 1 using the Biot-Savart law. Here, the distribution flux density through the center of cylindrical axis is expressed in Eq. $(7)_{3}$ (KIMIHIKO, 2002) as

$$
\begin{gathered}
\int d \vec{B}_{z}=\int_{-H_{m} / 2}^{H_{m} / 2} \int_{0}^{2 \pi} \frac{\mu_{0} I}{4 \pi r_{1}^{2}}\left(\frac{\sin \theta_{1}-\sin \theta_{2}}{r_{1}^{2}-r_{2}^{2}}\right) \\
\cdot R \mathrm{~d} \theta \mathrm{d} z\left(\widehat{u}_{\phi} \times \widehat{r}\right),
\end{gathered}
$$

where

$$
\begin{aligned}
R & =\frac{D_{m}}{2}, \\
r_{1} & =\sqrt{\left(z+\frac{H_{m}}{2}\right)^{2}+\left(\frac{D_{m}}{2}\right)^{2}}, \\
r_{2} & =\sqrt{\left(z-\frac{H_{m}}{2}\right)^{2}+\left(\frac{D_{m}}{2}\right)^{2}},
\end{aligned}
$$

$$
\begin{aligned}
B_{z}(z)= & B_{r}\left[\frac{z+\frac{D_{m}}{2}}{\sqrt{4\left(z+\frac{H_{m}}{2}\right)^{2}+D_{m}^{2}}}\right. \\
& \left.-\frac{z-\frac{D_{m}}{2}}{\sqrt{4\left(z-\frac{H_{m}}{2}\right)^{2}+D_{m}^{2}}}-C\right],
\end{aligned}
$$

where

$$
\left\{\begin{array}{l}
C=1\left(\frac{-H_{m}}{2}<z<\frac{H_{m}}{2}\right) \\
C=0\left(\frac{-H_{m}}{2}>z, \quad z>\frac{H_{m}}{2}\right) .
\end{array}\right.
$$




\subsection{The electromagnetic energy output}

According to Wang's analysis (WANG et al., 2010) and experimental work, the coil's optimal allocation can be obtained. Results reveal that the magnetic voltage will increase if the layer of the coil increases. In order to simplify the analysis, only a one-layer solenoid/winding coil is considered. In addition, the magnet will be placed at the center of the coil. According to Faraday's law, the individual induced voltage with respect to each circular coil yields

$$
\varepsilon=-\frac{\mathrm{d} \phi}{\mathrm{d} t}=-\frac{\pi D_{c}^{2}}{4} \frac{\mathrm{d} B_{z}}{\mathrm{~d} z} \cdot \frac{\mathrm{d} z}{\mathrm{~d} t}
$$

where

$$
\begin{aligned}
\frac{\mathrm{d} B_{z}(z)}{\mathrm{d} z}= & B_{r}\left[\frac{D_{m}^{2}}{\sqrt{\left[4\left(z+\frac{H_{m}}{2}\right)^{2}+D_{m}^{2}\right]^{3}}}\right. \\
& \left.-\frac{D_{m}^{2}}{\sqrt{\left[4\left(z-\frac{H_{m}}{2}\right)^{2}+D_{m}^{2}\right]^{3}}}\right] .
\end{aligned}
$$

Consequently, the total voltage induced by a moving magnet will be obtained by summing up all the coil's induced electrical voltages

$$
V_{\text {total }}=\sum_{n=0}^{N_{c}-1} \varepsilon_{n} .
$$

\subsection{Spring design}

\subsubsection{Spring ratio}

In order to reduce the influence of the magnetic force between the spring and the magnet, a steel spring (material: ASTM A311) with low permeability is selected in the experimental work. The related mechanical property of the steel spring is shown in Table 1.

Table 1. The related mechanical property of the steel spring.

\begin{tabular}{|c|l|c|c|}
\hline Symbol & \multicolumn{1}{|c|}{ Describe } & & Unit \\
\hline$\rho_{s}$ & Density & 7810 & $\mathrm{~kg} / \mathrm{m}^{3}$ \\
\hline$E$ & Modulus of Elasticity & $29 \times 10^{6}$ & $\mathrm{psi}$ \\
\hline$G$ & Modulus of Rigidity & $11 \times 10^{6}$ & $\mathrm{psi}$ \\
\hline$\sigma_{u l t}$ & Ultimate Tensile Strength & 120,000 & $\mathrm{psi}$ \\
\hline$\frac{\tau_{y p}}{\sigma_{u l t}}$ & $\begin{array}{l}\text { Ratio of yield strength in } \\
\text { shear }\end{array}$ & 0.46 & \\
\hline$\frac{\tau_{e}^{\prime}}{\sigma_{u l t}}$ & $\begin{array}{l}\text { Ratio of endurance limit in } \\
\text { shear to ultimate strength }\end{array}$ & 0.2 & \\
\hline
\end{tabular}

Moreover, the spring constant is expressed as (SpotTs, Shoup, 1998)

$$
k=\frac{G d_{s}^{4}}{8 D_{s}^{3} N_{a}} .
$$

\subsubsection{The spring's geometric relation}

As illustrated in Fig. 3, the spring used in the paper is a round-wire helical compression-spring. Because the helical angle is often set as $\pi / 10$, the spring pitch $\left(p_{s}\right)$ is expressed as

$$
p_{s}=2 D_{s} \tan \frac{\pi}{10}
$$
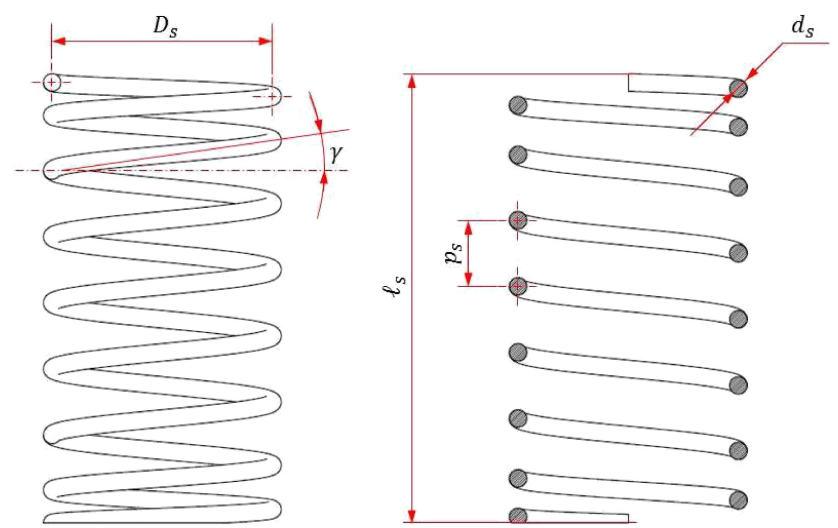

Fig. 3. A round-wire helical compression-spring.

The related minimum free length of the spring $\left(\ell_{S}\right)$ is

$$
\ell_{s}=p_{s} N_{a}+d_{s}
$$

where $d_{s}$ is the diameter of the spring wire and $N_{a}$ is the total number of revolutions.

\subsubsection{Spring buckling}

The helical compression spring may buckle when the spring deflection is too large or the free length of the spring is too long. According to SHIGLEY et al., the critical deflection is (SHIGLEY et al., 2008)

$$
\begin{aligned}
& y_{c r}=\ell_{s} C_{1}\left(1-\sqrt{1-\frac{C_{2}}{\lambda_{\text {eff }}^{2}}}\right), \\
& \lambda_{\text {eff }}=\frac{\alpha \ell_{s}}{D_{s}}, \\
& C_{1}=\frac{E}{2(E-G)}, \\
& C_{2}=\frac{2 \pi^{2}(E-G)}{2 G+E},
\end{aligned}
$$


where $y_{c r}$ is the deflection corresponding to the onset of instability and $\lambda_{\text {eff }}$ is the effective slenderness ratio. Because absolute stability will occur if the term $C_{2} / \lambda_{\text {eff }}^{2}$ in Eq. (13) $)_{1}$ is greater than unity, it yields

$$
1-\frac{2 \pi^{2} D_{s}^{2}(E-G)}{(2 G+E)\left(\alpha \ell_{s}\right)^{2}} \geq 0 .
$$

Rearranging Eq. (14) yields

$$
\ell_{s} \leq \frac{\pi D_{s}}{\alpha} \sqrt{\frac{2(E-G)}{2 G+E}} .
$$

\subsubsection{The spring's fluctuating load}

As indicated in Fig. 4, the maximal displacement of the upper spring and lower spring is the summation of the spring's pre-compressed displacement $\left(\delta_{\text {upper }} / \delta_{\text {lower }}\right)$ and the magnet's displacement. As indicated in Eq. (1), the magnet's maximal displacement is

$$
Z_{\max }=Z \sin (\omega t-\phi) \quad \text { at } \quad \sin (\omega t-\phi)=1 .
$$

a)

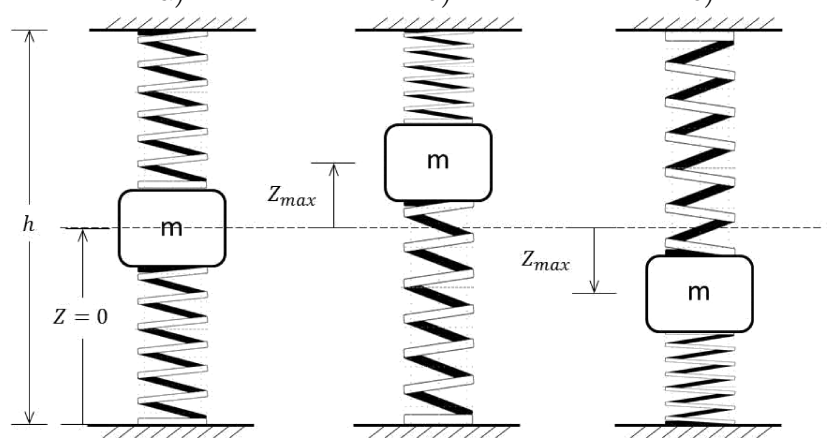

Fig. 4. The motion of the one-mass vibrational system.

The maximal displacement of the upper and lower springs is $\delta_{\text {upper }}+Z_{\max }$ and $\delta_{\text {lower }}+Z_{\max }$, accordingly. For a given magnet height $\left(H_{m}\right)$ and a free length of the spring $\left(\ell_{s}\right)$, the height of the inner housing $(h)$ yields

$$
\begin{aligned}
h= & {\left[l_{s}-\left(Z_{\max }+\delta_{\text {upper }}\right)\right]+H_{m} } \\
& +\left[l_{s}-\left(Z_{\max }+\delta_{\text {lower }}\right)\right] .
\end{aligned}
$$

The vertical force balance becomes

$$
\delta_{\text {lower }}-\delta_{\text {upper }}=\frac{m g}{k}
$$

Assuming $\delta_{\text {upper }}=0$, the lower spring precompressed displacement is simplified as

$$
\delta_{\text {lower }}=\frac{m g}{k} .
$$

The maximal compression of the spring is expressed as

$$
F_{\max }=k \delta_{\max }=m g+2 k Z_{\max } .
$$

A free-body diagram of axial loading on a helical spring is shown in Fig. 5.

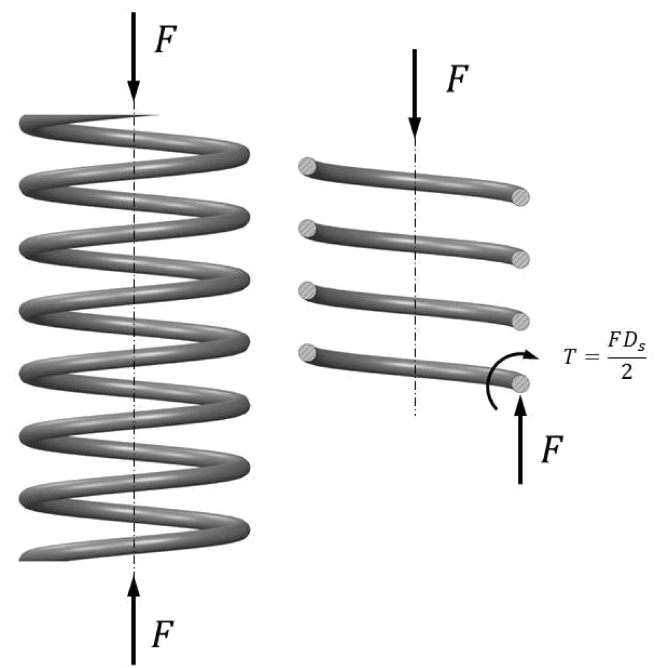

Fig. 5. A free-body diagram of axial loading on a helical spring.

The torsion's shear stress is expressed as

$$
\tau_{\max }=\frac{T r}{J}+\frac{F_{\max }}{A_{S}}
$$

where

$$
\begin{array}{rlrl}
T & =F_{\max } D_{S} / 2, & r & =D_{s} / 2, \\
J & =\pi d_{S}^{4} / 32, & A_{S}=\pi d_{S}^{2} / 4, \\
\tau_{\max } & =\frac{8 F_{\max } D_{S}}{\pi d_{S}^{3}}\left(1+\frac{d_{S}}{2 D_{S}}\right) . &
\end{array}
$$

Defining a spring index of $C_{0}=\frac{D_{s}}{d_{s}}$ yields

$$
\tau_{\max }=\tau=\frac{8 F_{\max } D_{s}}{\pi d_{s}^{3}}\left(1+\frac{1}{2 C_{0}}\right) .
$$

Equation (22) can be simplified as

$$
\tau=K_{S} \frac{8 F D_{S}}{\pi d_{S}^{3}}
$$

where $K_{S}$, a shear stress-correction factor, is set at $K_{S}=1+\frac{1}{2 C_{0}}$.

Equation (23) is deduced based on the linear relationship of the shear stress distribution shown in Fig. 6a. Considering the curvature effect of the shear stress distribution shown in Fig. 6 b, the $K_{S}$, a shear stress-correction factor, shall be replaced by $K_{C}$ (wahl factor) as shown below (SAmónOv, 1984)

$$
K_{C}=\frac{4 C_{0}-1}{4 C_{0}-4}+\frac{0.615}{C_{0}} .
$$


a)

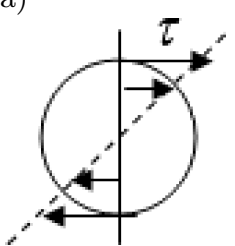

b)

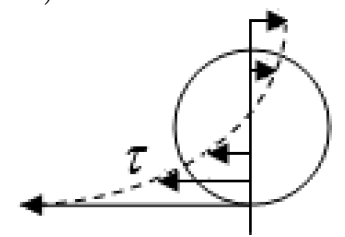

Fig. 6. Shear stress distribution in the spring wire: a) ideal relationship for the shear stress distribution in the spring wire, b) real relationship for the shear stress distribution in the spring wire.

To obtain more accurate data, the $K_{S}$ is replaced by $K_{C}$ (a Wahl factor). The fluctuating loading condition on the spring is

$$
\begin{aligned}
F_{a} & =\frac{F_{\max }-F_{\min }}{2}, \\
F_{m} & =\frac{F_{\max }+F_{\min }}{2}, \\
F_{r} & =F_{\min }+F_{a} .
\end{aligned}
$$

The related fluctuating stress of the spring illustrated in Fig. 7 is expressed as

$$
\begin{aligned}
\tau_{a} & =K_{C} \frac{8 F_{a} D_{S}}{\pi d_{S}^{3}}, \\
\tau_{m} & =K_{C} \frac{8 F_{m} D_{S}}{\pi d_{S}^{3}}, \\
\tau_{r} & =K_{C} \frac{8 F_{r} D_{S}}{\pi d_{S}^{3}} .
\end{aligned}
$$

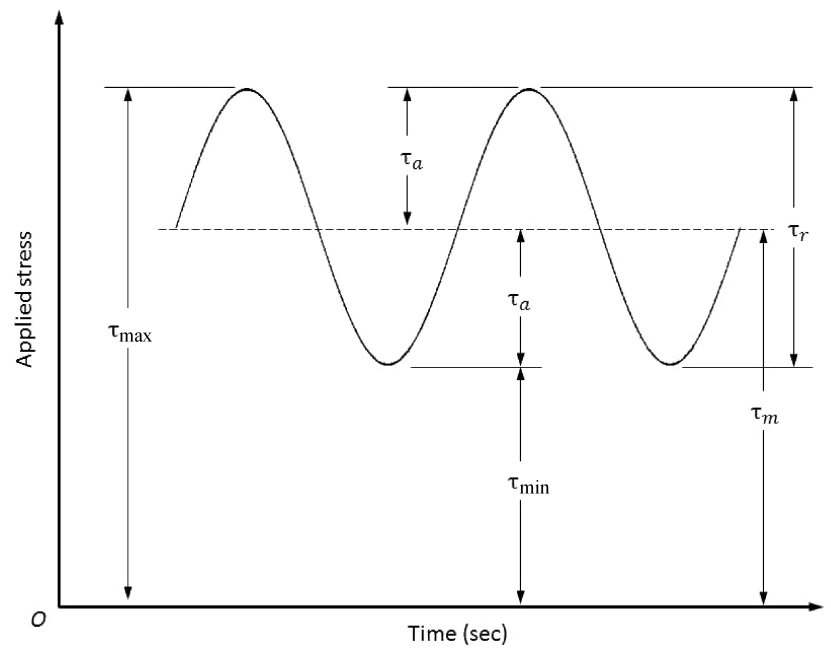

Fig. 7. The related stress-time diagram for a fluctuating load acting on the spring.

\subsubsection{Safety factor for fatigue}

Because of the fluctuating force acting on the spring during mechanical vibration, spring fatigue is a concern. The relationship between the safety factor and the fluctuating load is plotted in Fig. 8 (SPotTs, Shoup, 1998). As indicated in Fig. 8, line A is the minimum safety factor of 1 , and line $\mathrm{B}$, the working stress line, is the appropriate working area of the safety factor. The stress relationship at line B is expressed as

$$
\frac{K_{C} \tau_{a}}{\frac{\tau_{y p}}{F_{s}}-\tau_{m}}=\frac{\frac{1}{2} \tau_{e}^{\prime}}{\tau_{y p}-\frac{\tau_{e}^{\prime}}{2}} .
$$

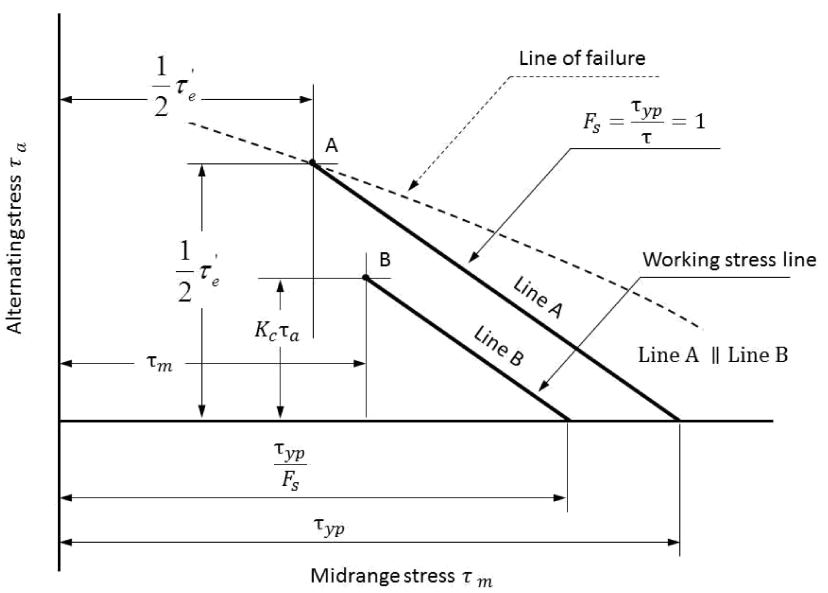

Fig. 8. The working stresses on fluctuating loading. ( $\tau$ : applied stress).

Rearranging Eq. (27) yields

$$
F_{s}=\frac{\tau_{y p}}{2\left(K_{C} \tau_{a}\right)\left(\frac{\tau_{y p}}{\tau_{e}^{\prime}}-1 / 2\right)+\tau_{m}} .
$$

\subsection{Objective function}

To optimally design a vibration-based electromagnetic energy harvester within a space-constrained situation, the objective function for harvesting electromagnetic power is

$$
O B J_{1}\left(D_{m}, H_{m}, N_{c}, \varsigma_{\text {sys }}\right)=\frac{1}{T} \int \frac{V^{2}(t)}{R_{\text {total }}} \mathrm{d} t .
$$

Concerning the influence of buckling on the spring, the penalty factor PN1 will be considered in the $O B J$ function. With this, a new $O B J$ yields

$$
O B J_{2}\left(D_{m}, H_{m}, N_{c}, \varsigma_{\text {sys }}\right)=O B J_{1} * \mathrm{PN} 1 .
$$

Here, the PN1 will be 1 if the free spring length meets the buckling criteria of $\ell_{s} \leq \frac{\pi D_{S}}{\alpha} \sqrt{\frac{2(E-G)}{2 G+E}}$ shown in Eq. (15). Contrarily, the PN1 will be set at 0.01 .

Similarly, considering the influence of fatigue induced by fluctuating stress, the penalty factor PN2 will 
be considered in the $O B J$ function. With this, a new $O B J$ yields

$$
O B J_{3}\left(D_{m}, H_{m}, N_{c}, \varsigma_{\mathrm{sys}}\right)=O B J_{1} * \mathrm{PN} 1 * \mathrm{PN} 2
$$

Here, the targeted safety factor $\left(F_{s}\right)$ is preset at 1.5. The PN2 will be 1 if the safety factor meets the criteria of $F_{s} \leq \frac{\tau_{y p}}{2\left(K_{C} \tau_{a}\right)\left(\frac{\tau_{y p}}{\tau_{e}}-1 / 2\right)+\tau_{m}}$ shown in Eq. (27). Otherwise, the PN2 will be set at 0.01 if $F_{s}>\frac{\tau_{y p}}{2\left(K_{C} \tau_{a}\right)\left(\frac{\tau_{y p}}{\tau_{e}}-1 / 2\right)+\tau_{m}}$ occurs.

\section{Case studies}

Four kinds of base vibrating sources (excited frequencies of $5 \mathrm{~Hz}, 10 \mathrm{~Hz}, 15 \mathrm{~Hz}$, and $20 \mathrm{~Hz}$ ) with the same displacement amplitude of $0.001(\mathrm{~m})$ are proposed. To optimally extract these vibrations using a spring-mass electromagnetic energy harvester, four kinds of design parameters, the magnet's height $\left(H_{m}\right)$, diameter $\left(D_{m}\right)$, the coil's number of revolutions $\left(N_{c}\right)$, and the damping ratio $\left(\zeta_{\text {sys }}\right)$, in conjunction with the $S A$ method are assessed in the following sections. The related ranges of the design parameters are shown in Table 2. In addition, the steel spring property is depicted in Table 1. Also, the property of the magnet and the coil is shown in Table 3. Moreover, a fixed mechanical damping ratio measured by the experimental work is 0.018 .

Table 2. The ranges of the design parameters.

\begin{tabular}{|c|c|c|}
\hline Design Parameters & Range & Unit \\
\hline$D_{m}$ & $0.005 \sim 0.02$ & $\mathrm{~m}$ \\
\hline$H_{m}$ & $0.005 \sim 0.03$ & $\mathrm{~m}$ \\
\hline$N_{C}$ & $10 \sim 500$ & \\
\hline$\zeta_{\text {sys }}$ & $0.5 \sim 0.02$ & \\
\hline
\end{tabular}

Table 3. The related physical property of the magnet and the coil.

\begin{tabular}{|c|l|c|c|}
\hline \multicolumn{4}{|c|}{ Neodymium Permanent Magnet } \\
\hline Symbol & \multicolumn{1}{|c|}{ Description } & & \\
\hline$\rho_{m}$ & $\begin{array}{l}\text { Neodymium magnet } \\
\text { density }\end{array}$ & $7.4 \times 10^{3}$ & $\mathrm{~kg} / \mathrm{m}^{3}$ \\
\hline$B_{r}$ & $\begin{array}{l}\text { Residual magnetic flux } \\
\text { density }\end{array}$ & 1.2 & Tesla \\
\hline \multicolumn{4}{|c|}{ Wounding Coil } \\
\hline$\rho_{C}$ & Electrical resistivity & $1.68 \times 10^{-8}$ & Ohm-m \\
\hline$R$ & Load resistor & 300 & Ohm \\
\hline
\end{tabular}

\section{Optimization process}

The $O B J$ function is linked with the Simulated Annealing Method. The basic concept behind $S A$ was first introduced by Metropolis et al. (1953) and devel- oped by KIRKPATRICK et al. (1983). The optimization flow diagram using the $S A$ method is depicted in Fig. 9.

As indicated in Fig. 9a, in order to find the best design parameter set $\left(H_{m}, D_{m}, N_{c}, \zeta_{\text {sys }}\right)$ to generate maximal electrical power, four design parameters are investigated within the given ranges. Based on the theoretical model derived in Eqs. (1)-(31), the predicted electrical power, the free length of the spring $\left(\ell_{S}\right)$, and the safety factor $\left(F_{s}\right)$ will be obtained. Moreover, the predicted spring constant $(k)$ will also be rechecked with the existing $k$ in the real world. The first loop of parameter searching will stop if the deviation of the predicted $k$ and the existing $k$ is equal to and less than 2 ; otherwise, the first loop of parameter searching will continue.

As indicated in Fig. 9b, concerning the buckling effect and the influence of the fluctuating stress, the free length of the spring $\left(\ell_{S}\right)$ and the safety factor $\left(F_{s}\right)$ will be rechecked in conjunction with the penalty factors of PN1 and PN2. PN1 and PN2 will be 1 if rechecking both the buckling effect and the safety factor is qualified; otherwise, the penalty factors of PN1 and PN2 will be 0.01 .

As indicated in Fig. 9c, for the SA optimization process, a new random solution $\left(X^{\prime}\right)$ will be chosen from the neighborhood of the current solution $(X)$. If the change in the objective function (or energy) is negative, i.e., $\Delta F \leq 0$, a new solution will be acknowledged as the new current solution with the transition property $p b\left(X^{\prime}\right)$ of 1 ; if it is not negative, then the new transition property $\left(p b\left(X^{\prime}\right)\right)$ varying from $0 \sim 1$ will be calculated using the Boltzmann factor $\left(p b\left(X^{\prime}\right)=\exp (\Delta F / C T)\right)$ as shown in Eq. (32)

$$
\begin{gathered}
p b\left(X^{\prime}\right)=\left\{\begin{array}{cc}
1 & \Delta F \leq 0, \\
\exp \left(\frac{-\Delta F}{C T}\right) & \Delta F>0,
\end{array}\right. \\
\Delta F=O B J\left(X_{n}^{\prime}\right)-O B J\left(X_{n}\right),
\end{gathered}
$$

where $C$ and $T$ are the Boltzmann constant and the current temperature. Additionally, compared to the new random probability of $\operatorname{rand}(0,1)$, if the transition property $\left(p b\left(X^{\prime}\right)\right)$ is greater than a random number of $\operatorname{rand}(0,1)$, the new uphill solution, which results in a higher energy condition, will be accepted; if not, it will be rejected. The uphill solution at a higher temperature will then have a better possibility of escaping from the local optimum. The algorithm reiterates the perturbation of the current solution and the measurement of change in the objective function. Each successful swap of the new current solution will point to the decay of the current temperature as

$$
T_{\text {new }}=k k \cdot T_{\text {old }},
$$

where $k k$ is the cooling rate. The process is reiterated until the predetermined number $\left(\right.$ iter $_{\max }$ ) of the outer loop is reached. 
a)

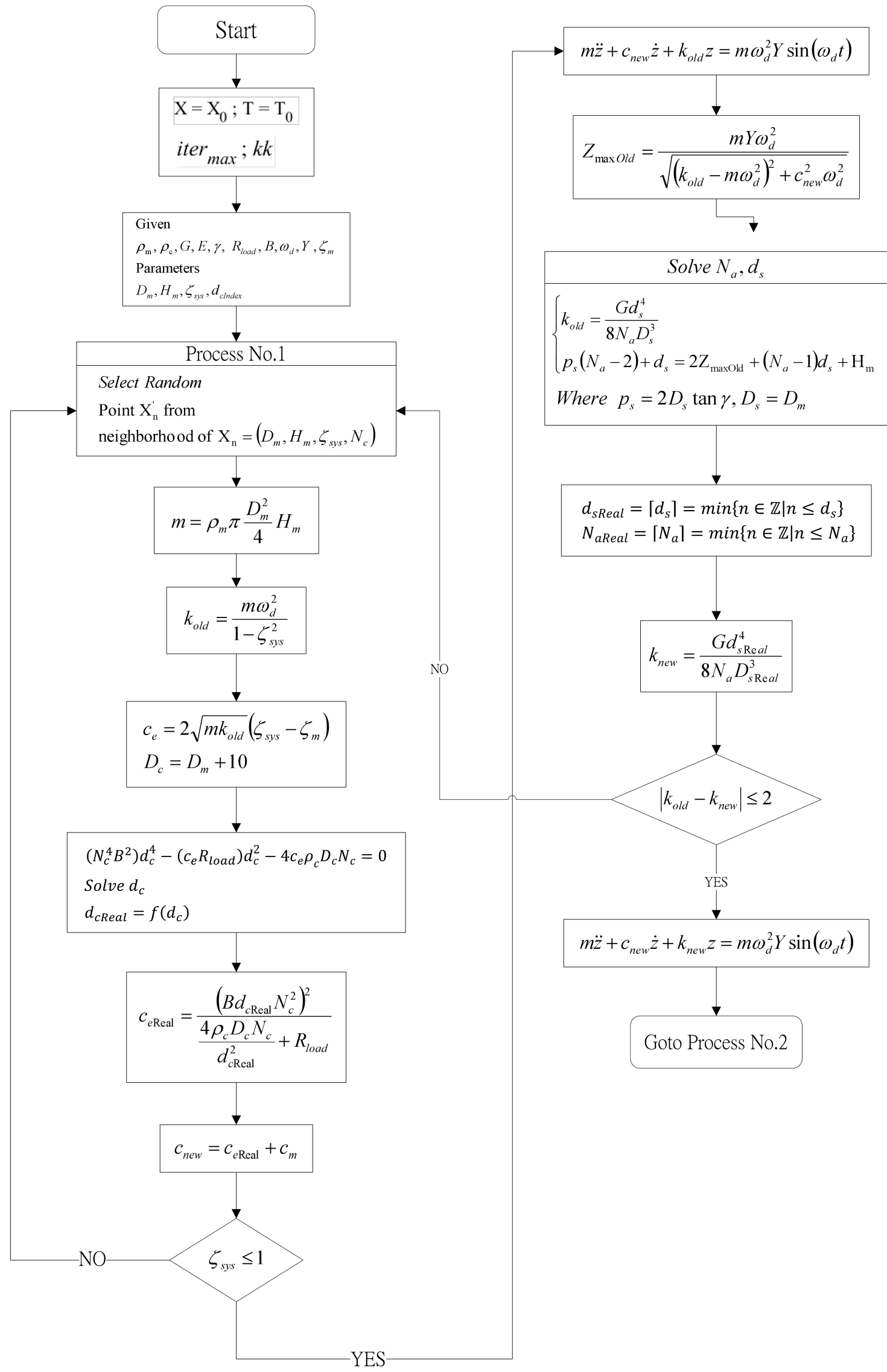

[Fig. 9a] 
b)

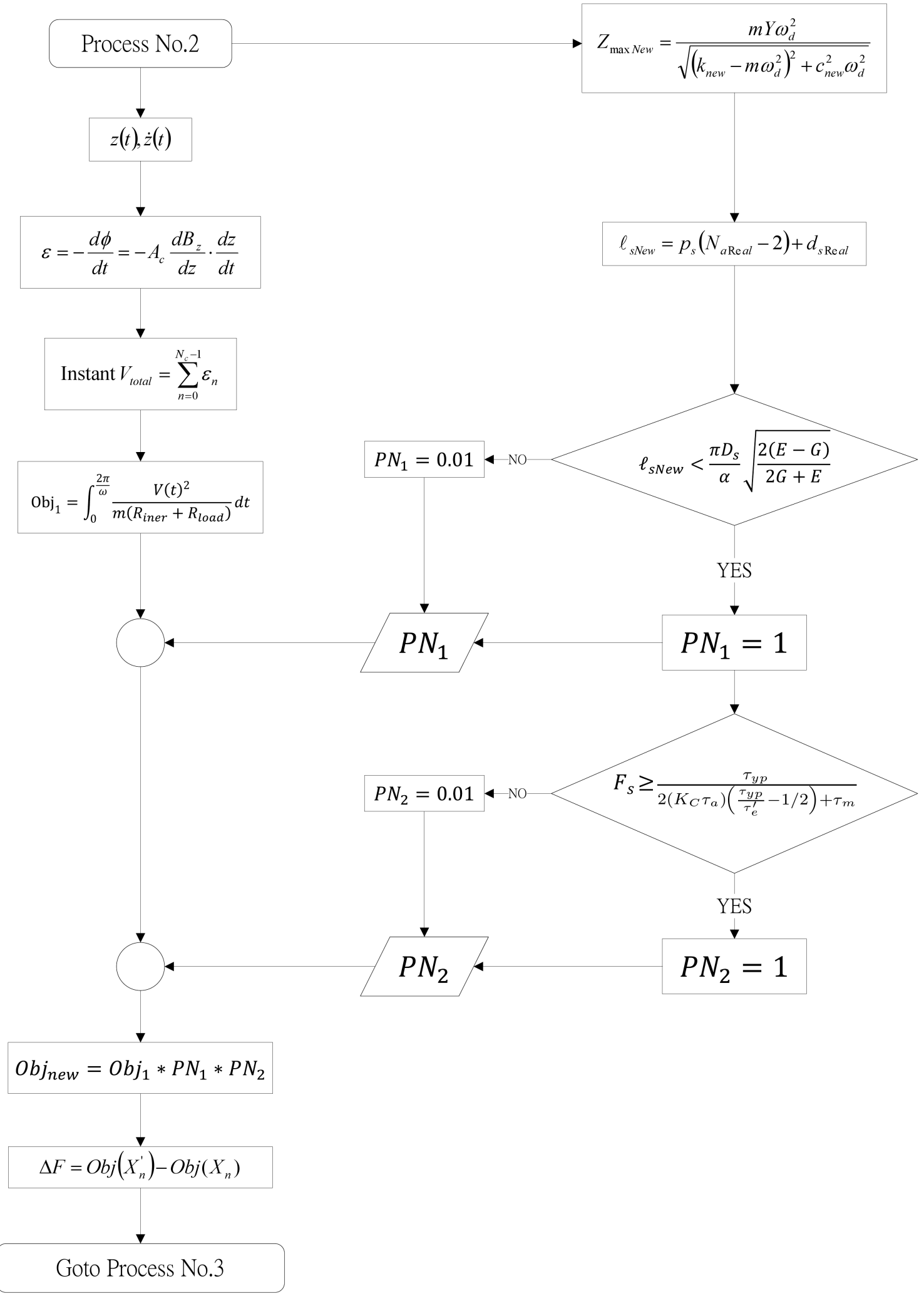

[Fig. 9b] 
c)

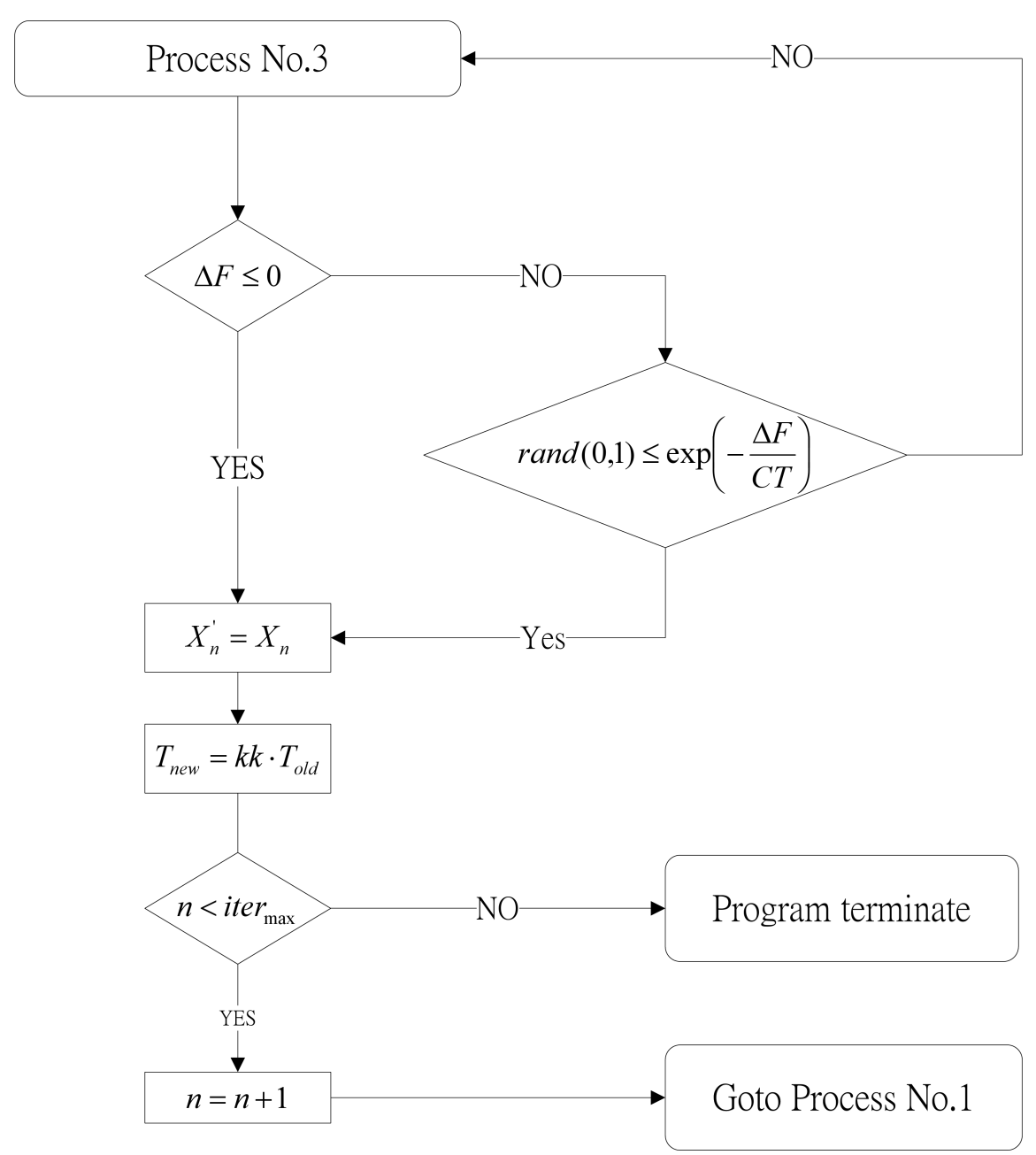

Fig. 9. The optimization diagram using the SA method: a) part I (PROCESS No. 1), b) part II (PROCESS No. 2), c) part III (PROCESS No. 3).

\section{Results and discussion}

The accuracy of the $S A$ optimization depends on the $k k$ (cooling rate) and the iter $_{\max }$ (maximum iteration number). To investigate the influence of the above $S A$ 's control parameters, assessed ranges of the $S A$ parameters are

$k k=(0.91,0.92,0.93,0.94,0.95,0.96,0.97,0.98,0.99)$;

iter $_{\max }=(100,200,400,800,1600,3200,6400,12800)$.

\subsection{Results}

For a base-vibrating system excited by a frequency of $20 \mathrm{~Hz}$, the optimal results by varying the $S A$ 's control parameters $(k k$, iter $\max )$ are shown in Table 4. As indicated in Table 4, the optimal design data can be obtained when the $S A$ parameters at $\left(k k\right.$, iter $\left._{\max }\right)=(0.99,12800)$ are applied. Additionally, in order to understand the real influence of the electrical power with respect to the design parameters $\left(D_{m}, H_{m}, N_{c}\right.$ and $\left.\varsigma_{\text {sys }}\right)$, an assessment of said influence on the electrical power with respect to four design parameters is carried out and plotted in Fig. 10. As indicated in Fig. 10, a ratio of the design parameter to its maximal value is set at the $x$-axis while the related electrical power is set at the $y$-axis. Figures 10a and $10 \mathrm{~b}$ indicate that maximal electrical power will occur at the appropriate values of the $D_{m}$ and $H_{m}$, which cause a resonance by approaching the natural frequency to the external vibration frequency. Moreover, Fig. 10c also indicates that the electrical power will increase if the system's damping ratio $\left(\varsigma_{\text {sys }}\right)$ increases. Furthermore, as shown in Fig. 10d, maximal electrical power will occur at a middle value within the revolving coil $\left(N_{c}\right)$. This is because a larger number of revolutions will result in more electrical power; however, the coil's retarding force induced by the electromagnet field will increase and the related kinetic motion will decrease. With this, the resulting electrical power will decrease. Therefore, the interaction between the retarding force and the kinetic motion will result in an appropriate coil's number of revolutions $\left(N_{c}\right)$. 
Table 4. Optimal $\mathrm{OBJ}_{3}(\mathrm{~J})$ for the vibration-based electromagnetic energy harvester at various $k k$ and $i_{\text {ter }}$ max (at a targeted tone of $20 \mathrm{~Hz}$ and an amplitude of $0.05 \mathrm{~m}$ ).

\begin{tabular}{|c|c|c|c|c|c|c|}
\hline \multicolumn{2}{|c|}{$\begin{array}{c}\text { SA control } \\
\text { parameters }\end{array}$} & \multicolumn{3}{c|}{ Design parameters } & Results \\
\hline$k k$ & iter $_{\max }$ & $\begin{array}{c}H_{m} \\
{[\mathrm{~m}]}\end{array}$ & $\begin{array}{c}D_{m} \\
{[\mathrm{~m}]}\end{array}$ & $\zeta_{\text {sys }}$ & $N_{C}$ & $\begin{array}{c}\text { OBJ } \\
{[\text { Watt }]}\end{array}$ \\
\hline 0.9 & 100 & 0.0137 & 0.0275 & 0.011852 & 18 & 0.00538 \\
\hline 0.91 & 100 & 0.0128 & 0.0191 & 0.01656 & 66 & 0.01908 \\
\hline 0.92 & 100 & 0.0196 & 0.0265 & 0.016664 & 87 & 0.01973 \\
\hline 0.93 & 100 & 0.0109 & 0.0291 & 0.030385 & 110 & 0.01295 \\
\hline 0.94 & 100 & 0.0185 & 0.0153 & 0.058937 & 115 & 0.00374 \\
\hline 0.95 & 100 & 0.0119 & 0.0118 & 0.019125 & 57 & 0.00482 \\
\hline 0.96 & 100 & 0.0205 & 0.0284 & 0.022702 & 112 & 0.0188 \\
\hline 0.97 & 100 & 0.0164 & 0.0174 & 0.017172 & 69 & 0.0299 \\
\hline 0.98 & 100 & 0.009 & 0.0164 & 0.031719 & 80 & 0.00885 \\
\hline 0.99 & 100 & 0.0147 & 0.0185 & 0.015749 & 64 & 0.03187 \\
\hline$\underline{0.99}$ & 200 & 0.0123 & 0.0156 & 0.024744 & 76 & 0.01177 \\
\hline$\underline{0.99}$ & 400 & 0.0082 & 0.0177 & 0.014925 & 51 & 0.00981 \\
\hline$\underline{0.99}$ & 800 & 0.0133 & 0.0249 & 0.01346 & 58 & 0.03983 \\
\hline$\underline{0.99}$ & 1600 & 0.0164 & 0.0245 & 0.014548 & 69 & 0.06015 \\
\hline$\underline{0.99}$ & 3200 & 0.0195 & 0.029 & 0.015537 & 85 & 0.0627 \\
\hline$\underline{0.99}$ & 6400 & 0.0258 & 0.0243 & 0.022354 & 108 & 0.09437 \\
\hline$\underline{0.99}$ & 12800 & 0.0287 & 0.0298 & 0.014854 & 90 & 0.16065 \\
\hline
\end{tabular}

a) influence of electrical power vs $H_{m}$

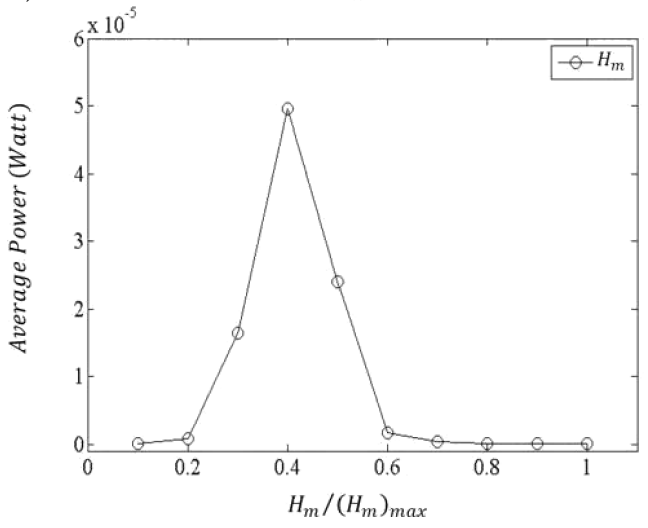

c) influence of electrical power vs $\varsigma_{\text {sys }}$

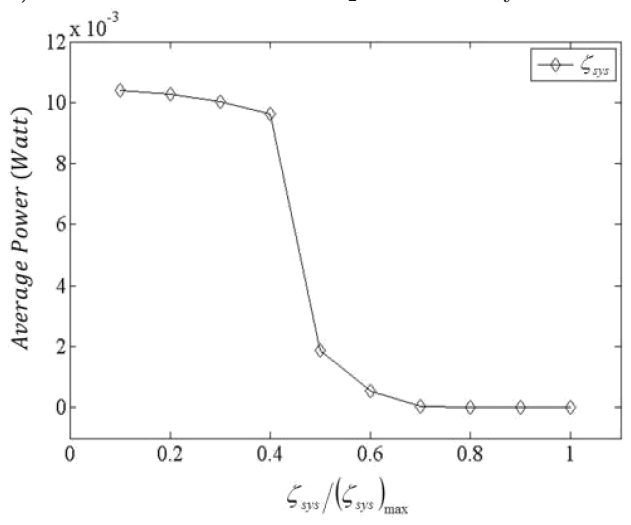

b) influence of electrical power vs $D_{m}$

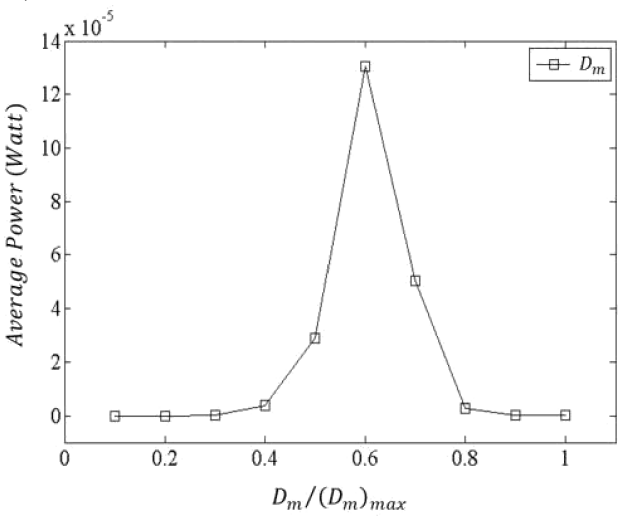

d) influence of electrical power vs $N_{c}$

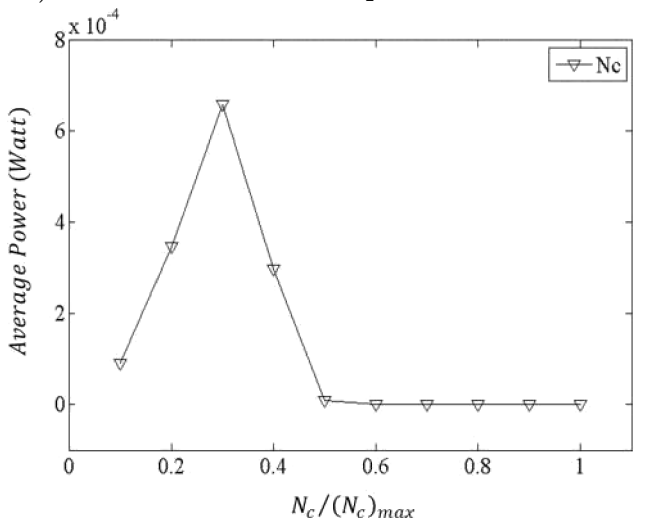

Fig. 10. Influence of electrical power with respect to designed parameters. 
Table 5. The optimal design of the electrical power for four kinds of forcing frequencies

(Case I $\sim$ Case IV) at $k k=0.99$ and $i t e r_{\max }=12800$.

\begin{tabular}{|c|c|c|c|c|c|}
\hline \multirow{2}{*}{ Cases } & \multicolumn{4}{|c|}{ Design parameters } & Results \\
\cline { 2 - 6 } & $\begin{array}{c}H_{m} \\
{[\mathrm{~m}]}\end{array}$ & $\begin{array}{c}D_{m} \\
{[\mathrm{~m}]}\end{array}$ & $\zeta_{\text {sys }}$ & $N_{C}$ & $\begin{array}{c}\mathrm{Obj}_{3} \\
{[\text { Watt }]}\end{array}$ \\
\hline$f_{\text {in }}=5[\mathrm{~Hz}]$ & 0.0187 & 0.0246 & 0.026246 & 184 & 0.01187 \\
\hline$f_{\text {in }}=10[\mathrm{~Hz}]$ & 0.0205 & 0.0276 & 0.04008 & 303 & 0.04238 \\
\hline$f_{\text {in }}=15[\mathrm{~Hz}]$ & 0.0274 & 0.0299 & 0.020549 & 108 & 0.0793 \\
\hline$f_{\text {in }}=20[\mathrm{~Hz}]$ & 0.0287 & 0.0298 & 0.014854 & 90 & 0.16065 \\
\hline
\end{tabular}

Table 6. The related design values of the energy harvester at four kinds of forcing frequencies $($ Case I Case IV) at $k k=0.99$ and iter $_{\max }=12800$.

\begin{tabular}{|c|c|c|c|c|c|c|c|}
\hline \multirow{2}{*}{ Cases } & \multicolumn{7}{|c|}{ Design values of the energy harvester } \\
\cline { 2 - 8 } & $\begin{array}{c}d_{C} \\
{[\mathrm{~m}]}\end{array}$ & $\begin{array}{c}k \\
{[\mathrm{~N} / \mathrm{m}]}\end{array}$ & $\begin{array}{c}d_{S} \\
{[\mathrm{~m}]}\end{array}$ & $\begin{array}{c}D_{S} \\
{[\mathrm{~m}]}\end{array}$ & $\begin{array}{c}p_{S} \\
{[\mathrm{~m}]}\end{array}$ & $N_{a}$ & $\begin{array}{c}\ell_{S} \\
{[\mathrm{~m}]}\end{array}$ \\
\hline$f_{\text {in }}=5[\mathrm{~Hz}]$ & 0.00011 & 65.05289 & 0.00092 & 0.0246 & 0.015986 & 7 & 0.08085 \\
\hline$f_{\text {in }}=10[\mathrm{~Hz}]$ & 0.0001 & 359.2126 & 0.001479 & 0.0276 & 0.017936 & 6 & 0.073221 \\
\hline$f_{\text {in }}=15[\mathrm{~Hz}]$ & 0.0006 & 1273.084 & 0.002315 & 0.0299 & 0.01943 & 8 & 0.118896 \\
\hline$f_{\text {in }}=20[\mathrm{~Hz}]$ & 0.0006 & 2377.598 & 0.00278 & 0.0298 & 0.019365 & 9 & 0.138337 \\
\hline
\end{tabular}

Using the same control parameters $\left(k k\right.$, iter $\left._{\max }\right)$ in the design data of the base-vibrating system with frequencies of $10 \mathrm{~Hz}, 15 \mathrm{~Hz}$, and $20 \mathrm{~Hz}$, the final simulated results with different frequencies $(5 \mathrm{~Hz}, 10 \mathrm{~Hz}$, $15 \mathrm{~Hz}$, and $20 \mathrm{~Hz}$ ) are shown in Table 5 . As indicated in Table 5, the optimal $O B J_{3}$ functions (electrical average power) with respect to various targeted frequencies $(5 \mathrm{~Hz}, 10 \mathrm{~Hz}, 15 \mathrm{~Hz}$, and $20 \mathrm{~Hz})$ are $0.012(\mathrm{~W})$, $0.042(\mathrm{~W}), 0.0793(\mathrm{~W})$, and $0.161(\mathrm{~W})$. Moreover, the design data for other parameters such as $d_{c}, k, d_{s}, D_{s}$, $P_{s}, N_{a}$, and $\ell_{S}$ are shown in Table 6 .

\subsection{Discussion}

For a space-constrained base-vibration system excited with a specific frequency, a spring-mass electromagnetic energy harvester is attached to the basevibration system. In order to reduce the influence of the magnetic force between the spring and the magnet, a steel spring (material: ASTM A313) with low permeability is selected in the experimental work.

In the spring-mass electromagnetic energy harvester, the reciprocating vibrational motion of the permanent magnet is coupled when the electrical power equation occurs. The electromechanical system is coupled with the electromagnetic field. On the basis of the Faraday's law and Lenz's law, the outputted electrical power of the coil will be proportional to the magnetic flux variance; however, the retarding force (damping effect) for the mechanical motion will increase if the coil's revolution number increases.
In order to find the optimal mechanism for the energy harvester that produces maximal electrical power, the electrical power is set as an objective function. Ten design parameters of the energy harvester including the magnet diameter $\left(D_{m}\right)$, the magnet height $\left(H_{m}\right)$, the system damping ratio $\left(\zeta_{\mathrm{sys}}\right)$, the spring diameter $\left(D_{S}\right)$, the diameter of the spring wire $\left(d_{S}\right)$, the spring length $\left(\ell_{S}\right)$, the pitch of the spring $\left(p_{S}\right)$, the spring's revolution number $\left(N_{a}\right)$, the coil diameter $\left(D_{C}\right)$, the diameter of the coil wire $\left(d_{C}\right)$, and the coil's revolution number $\left(N_{C}\right)$ are established. Concerning the geometric allocation, the above ten design parameters are reduced to four parameters $\left(D_{m}\right.$ : the magnet diameter; $H_{m}$ : the magnet height; $\zeta_{\text {sys }}$ : the system damping ratio; and $N_{C}$ : the coil's revolution number).

Concerning the buckling effect for the spring, the critical deflection from Shigley et al. (2008) is adopted and used in the spring design work. Similarly, concerning the influence of fatigue induced by fluctuating stress, the predicted safety factor will be rechecked.

Moreover, as can been seen in Table 4, the optimal design data can be obtained when the $S A$ parameters at $\left(k k\right.$, iter $\left.r_{\max }\right)=(0.99,12800)$. As indicated in Table 5 , the optimal value of the energy with respect to various targeted frequencies $(10 \mathrm{~Hz}, 15 \mathrm{~Hz}$, and $20 \mathrm{~Hz})$ is $0.042(\mathrm{~W}), 0.0793(\mathrm{~W})$, and $0.161(\mathrm{~W})$. It is obvious that the captured electrical energy will be proportional to the weight of the magnet. The damping coefficient increases while the coil's number of revolutions increases. Furthermore, the averaged electrical power will also be influenced by the vibration input induced by the environment. 


\section{Conclusion}

It has been shown that $S A$ can be used in the optimization of a space-constrained vibration-based electromagnetic energy harvester. The $S A$ parameters of the $k k$ (cooling rate) and the $i_{\text {ter }}$ max (maximum iteration number) are essential during the $S A$ optimization. The higher $i$ iter $_{\max }$ will result in a better solution.

Concerning the geometric allocation, four parameters $\left(D_{m}\right.$ - the magnet diameter; $H_{m}$ - the magnet height; $\zeta_{\text {sys }}$ - the system damping ratio; and $N_{C}$ - the coil's revolution number) are adopted for maximization of electrical power.

Concerning the buckling effect for a spring that will consume the vibrational energy and damage the spring, a critical deflection is included in the optimization using a penalty factor of PN1. Thus, concerning the influence of fatigue induced by fluctuating stress, the safety factor will be rechecked using a penalty factor PN2 in the SA optimization. The assessment of optimal energy extraction at four frequencies $(5 \mathrm{~Hz}$, $10 \mathrm{~Hz}, 15 \mathrm{~Hz}$, and $20 \mathrm{~Hz}$ ) is considered. Results reveal that the extracted electrical energy will increase when the frequency of the base-vibrating system increases.

Consequently, on the basis of the fatigue and buckling analysis, the approach used for an optimal designed one-mass vibration-based electromagnetic energy harvester proposed in this study is quite efficient in maximizing the energy $\left(O B J_{3}\right)$ within a spaceconstrained situation.

\section{Acknowledgments}

The authors acknowledge the financial support of the National Science Council (NSC 100-2221-E-036019), ROC.

\section{References}

1. Chiu M.C., Chang Y.C., Yeh L.J., Chung C.H. (2012), Optimal design of a vibration-based electromagnetic energy harvester using a simulated annealing algorithm, J. of Mechanics, 28, 4, 691-700.

2. Kiminiko N., Takashi S., Atsushi N., Tomohiro K. (2002), Portable electrodynamic generator using vi- bration on walking human body, Electromagnetics Symposium Proceedings, 14, 347-350.

3. Kirkpatrick S., Gelatt C.D. Jr., Vecchi M.P. (1983), Optimization by simulated annealing, Science, 220, 4598, 671-680.

4. Metropolis A., Rosenbluth W., Rosenbluth M.N., Teller H., Teller E. (1953), Equation of static calculations by fast computing machines, The Journal of Chemical Physics, 21, 6, 1087-1092.

5. Mikolanda T. (2009), Study of Permanent Magnets Force Interaction, Ph. D. Thesis, Technická Univerzita v Liberci.

6. Mitcheson P.D., Green T.C., Yeatman E.M., Holmes A.S. (2004), Architectures for vibrationdriven micropower generators, Journal of Microelectromechanical Systems, 13, 429-440.

7. Mitcheson P.D., Yeatman E.M., RaO G.K., Holmes A.S., Green T.C. (2008), Energy harvesting from human and machine motion for wireless electronic devices, IEEE, 96, 1457-1486.

8. Park J.C., Bang D.H., PARK J.Y. (2010), Microfabricated electromagnetic power generator to scavenge low ambient vibration, IEEE Transactions on Magnetics, 46, 6, 1937-1942.

9. Samónov C. (1984), Some aspects of design of helical compression springs, Int. Symp. Design and Syhthesis, Tokyo.

10. Shigley J.E., Mischke C.R. Budynax R.G. (2008), Shigley's mechanical engineering design 9th Edition, McGraw Hill.

11. Spotts M.F., Shoup T.E. (1998), Design of machine elements, 7th edition, page 259-260, Prentice-Hall, Inc.

12. Stephen N.G. (2006), On energy harvesting from ambient vibration, Journal of Sound and Vibration, 293, 409-425.

13. Wang Y.J., Chen C.D., Sung C.K. (2010), Design of a frequency-adjusting device for harvesting energy from a rotating wheel, Sensors and Actuators A, 159, 196-203.

14. Williams C.B., Pavic A., Crouch R.S., Woods R.C. (1997), Feasibility study of vibration-electric generator for bridge vibration sensor, the 16th International Modal Analysis Conference (IMAC XVI), Santa Barbara, CA, USA. 